Nunt. Antiquus, Belo Horizonte, v. 14, n. 1, p. 9-30, 2018

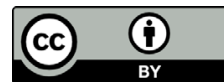

\title{
La recepción clásica en el teatro cubano del siglo XXI: la "tetralogía" de Yerandy Fleites
}

\author{
Classic Reception in the Cuban Theater of \\ the $21^{\text {st }}$ Century: the "Tetralogy" of Yerandy Fleites
}

\author{
Elina Miranda Cancela \\ Universidad de La Habana, La Habana / Cuba \\ elina@fayl.uh.cu
}

Resumen: Si bien desde mediados del siglo XX aparecen Antígonas, Electras, Medeas en la dramaturgia latinoamericana, ciertamente en el teatro cubano, después de un primer momento en los años sesenta en que se escriben o estrenan un buen número de tales versiones, es a partir de fines de los noventa y, sobre todo, en este siglo XXI, cuando el teatro cubano conoce un segundo auge en relación con la recepción clásica. Destaca el propósito de Yerandy Fleites, un joven dramaturgo, de escribir una especie de tetralogía sobre heroínas clásicas muy jóvenes: Antígona, Electra, Medea e Ifigenia. Comienza este proyecto alrededor de 2005, publica Antígona en 2007; Jardín de héroes, su versión de Electra, en 2009; Un bello sino, en torno a Medea, en 2010; mientras que la aparición de su Ifigenia (tragedia ayer) demora hasta el 2015. Analizar en estas cuatro obras las estrategias de recepción, marcadamente metateatrales, paródicas y de vínculos intertextuales multifacéticos, es el propósito asumido a fin de mostrar cómo se mantiene el diálogo con los clásicos, con variantes en relación a los recursos y perspectivas asumidos generalmente en la pasada centuria, pero con un propósito semejante de apropiación con vista a generar creativamente una nueva versión que no solo plasme sino haga reflexionar sobre inquietudes inherentes al momento y entorno social del autor.

Palabras claves: Recepción clásica; teatro cubano siglo XXI; Yerandy Fleites; tetralogía. 
Abstract: Although in the mid-20 $0^{\text {th }}$ century Antigones, Electras and Medeas appear in the Latin-American drama, in the Cuban theater, after a first moment in the sixties in which a good number of such versions were written or premiered, it is from the end of the nineties and, most of all, in this $21^{\text {st }}$ century, that certainly the Cuban theater knows a second boom in classic reception. It is remarkable the intention of Yerandy Fleites, a young playwright who wrote a sort of tetralogy about very young classic heroines: Antigone, Electra, Medea and Iphigenia. He began this project around 2005, he publishes Antigona in 2007; Jardin de héroes, his version of Electra, in 2009; and Un bello sino, about Medea, in 2010. The publications of Ifigenia (tragedia ayer), however, was delayed until 2015. These works are markedly metatheatrical, parodic and with multifaceted links of intertextuality. Analysing the reception strategies in these four works is the purpose assumed by this paper in order to point out how they maintain their dialogue with the Classics. The objective is to point at variations concerning the resources and perspectives generally assumed in the past century, but that reveal a similar intention of appropriation aimed to creatively generating a new version. A new verson that will both express and reflect about concerns inherent to the historical moment and social context of its author.

Keywords: Classic reception; Cuban theater $21^{\text {st }}$ century; Yerandy Fleites; tetralogy.

Desde fines del pasado siglo los estudios de recepción clásica en América Latina se han acrecentado notablemente, como demuestran las publicaciones y encuentros científicos - coloquios, congresos, talleres - que se han convocado sobre el tema tanto en la propia Iberoamérica como en el ámbito anglosajón. Mas, si bien el término recepción ha ganado terreno frente al de tradición, adoptado principalmente a partir del libro de Gilbert Highet, no deja de discutirse en la presente centuria otras propuestas ${ }^{1}$ más acordes con la variedad en el modo de asumirla, al tiempo que el espectro de manifestaciones abarcado rebasa los límites usuales de la literatura y el teatro. ${ }^{2}$ Ambas denominaciones son

\footnotetext{
${ }^{1}$ Se habla de transculturación, hibridismo, antropofagia, perversión, reciclaje, entre otros.

${ }^{2}$ En los últimos tiempos, bajo el acápite de tradición clásica encontramos el análisis de su presencia no solo en las letras, sino en las llamadas bellas artes; pero también en el cine, en seriales, en historietas ilustradas y también en tal término se incluyen reflexiones en torno a la enseñanza de las lenguas clásicas, la filología, las traducciones de obras de la Antigüedad grecorromana.
} 
igualmente amplias, aunque tradición apunta a un proceso unidireccional mientras que recepción supone el diálogo entablado entre clásicos y contemporáneos, enriquecedor de la comprensión y modo de interpretar tanto los modelos como las versiones, razón por la cual resulta preferible.

La pasada centuria fue particularmente prolija en cuanto a la presencia de la tragedia ática como trasfondo de obras teatrales, posiblemente porque los dramaturgos se sentían inclinados, más que a contar los hechos, a buscar explicaciones, tal como procuraran los grandes trágicos del siglo $\mathrm{V}$ ateniense. Sin embargo, aunque se apropiaban de sus modelos con gran libertad, primaba en su enfoque un éthos serio, tal como se constata en las obras de dramaturgos franceses cuya producción a veces se calificaba de neohelénica.

Desde mediados del siglo XX aparecen también Antígonas, Electras, Medeas en la dramaturgia latinoamericana y aunque en estas versiones se asumen múltiples variantes en cuanto al tratamiento del modelo, ciertamente en el teatro cubano es a partir de los años finales de la década del noventa $\mathrm{y}$, sobre todo, en este siglo XXI, cuando la conciencia metateatral es ampliamente subrayada, lo que no es óbice para que se mantengan los personajes con ropajes griegos o se procure una indeterminación en cuanto a la ubicación de la trama. En ocasiones ya la relación con la pieza clásica no es directa: bien al superponerse, como capa intermedia, una versión contemporánea que, a su vez, ha devenido modelo; bien cuando se apela a conjugar distintos elementos provenientes del mundo clásico - entre sí y aun mezclado con otros contemporáneos -, o a otras posibilidades en que la tradición conformada en el imaginario cultural a partir de la tragedia ática ocupa un primer plano o en que héroes y heroínas devienen meros estereotipos de determinada cualidad o de algún motivo circunstancial.

Ciertamente en el teatro cubano la obra que a mediados del siglo XX proyecta la dramaturgia nacional hacia la contemporaneidad es precisamente una versión de una tragedia clásica, Electra Garrigó, de Virgilio Piñera, pieza desacralizadora en la cual se fusionan características de diversos géneros teatrales y repertorios culturales, metateatral mucho antes que tal concepto se plasmara, al tiempo que en alguna medida propició que en los años sesenta se estrenaran como parte de esa escena 
cubana emergente un número proporcionalmente considerable de obras que partían de modelos griegos, posiblemente como medio de trascender el costumbrismo local, mostrar su valía al parangonarse con un quehacer consagrado en la opinión pública, pero sobre todo ofrecer una nueva perspectiva y hacer reflexionar sobre problemas de nuestra sociedad que por cotidianos no atraían la atención necesaria. ${ }^{3}$

Sin embargo, tales versiones prácticamente desaparecen en los setenta y los ochenta, con alguna excepción notable, ${ }^{4}$ hasta que desde fines de los noventa y sobre todo en los tres primeros lustros de la actual centuria de nuevo se escriben y se estrenan versiones de los clásicos en una proporción apreciable. ${ }^{5} \mathrm{Si}$ bien entre sus autores encontramos figuras reconocidas por su quehacer teatral en la pasada centuria, también aparecen jóvenes dramaturgos que precisamente se dan a conocer y asientan sus nombres en la historia teatral de estos años con obras sustentadas en antiguas tragedias, pero en especial resalta Yerandy Fleites, quien da a conocer su Antígona en 2007, justamente cuando acaba de terminar sus estudios de Teatrología en el Instituto Superior de Arte, al tiempo que anuncia su propósito de completar una especie de tetralogía, iniciada por esta obra, en que sus protagonistas serían heroínas trágicas muy jóvenes. Con este propósito en mente publica en 2009 Jardín de héroes, su versión de Electra, y Un bello sino, en torno a Medea, en

\footnotetext{
${ }^{3}$ En los años sesenta no solo se reestrena Electra Garrigó, con gran éxito de público, sino que suben a escena Medea en el espejo, de José Triana, Réquiem por Yarini, de Carlos Felipe, María Antonia, de Eugenio Hernández Espinosa, se publica Los siete contra Tebas, de Antón Arrufat, y Abelardo Estorino escribe Los tiempos de la plaga. Sobre estas obras cf. MIRANDA, 2006. Sobre el papel de la Electra Garrigó cf. MIRANDA, 2015. Sobre las obras citadas, cf. MIRANDA, 2006.

${ }^{4}$ En 1980 se estrenó Carnaval de Orfeo, de José Milián, y en 1986 sube escena La aprendiz de bruja, de Alejo Carpentier, pero escrita mucho antes.

${ }^{5}$ Antígona, del Grupo Estudio Teatral Santa Clara, se estrena en 1994; Medea, de Reinaldo Montero, en 1997, pero ya en este siglo tenemos Bacantes, de Flora Lauten y Raquel Carrió, Ícaros, de Norge Espinosa, Medea reloaded, de Maikel Rodríguez de la Cruz, Medea sueña Corinto, de Abelardo Estorino, Antígona, de Reinaldo Montero, Los Atridas y Casandra, Grupo Estudios Teatral Santa Clara, Áyax y Casandra, de Reinaldo Montero, a las cuales se suman las de Yerandy Fleites y otras de las que noticias, pero que no se han editado o representado todavía.
} 
2010, mientras que la aparición de su Ifigenia (tragedia ayer) demora hasta el 2015. Con ello no solo cumple su propósito, sino que se torna el autor con mayor número de versiones de piezas griegas en el lapso de aproximadamente una década, ${ }^{6}$ si tenemos en cuenta que comenzó a escribir las primeras en 2005, según el propio autor, al tiempo que podemos considerarlas como una especie de tetralogía, en cuanto las une el deseo explícito del dramaturgo de escribir sobre estas heroínas, muy jóvenes todas pero abocadas a enfrentar conflictos trágicos.

Cuando aparece publicada su Antígona en la revista Tablas, ${ }^{7}$ Yerandy Fleites, nacido en 1982, también es muy joven, con sus veinticinco años. ${ }^{8}$ Sin embargo ya ha obtenido reconocimientos, como una mención en el concurso David de la Unión Nacional de Escritores y Artistas de Cuba (UNEAC) con su obra Un bello sino y el premio Calendario de ese mismo año con Jardín de héroes, dedicada por el autor a los sesenta años de Electra Garrigó.

Si bien la Antígona griega es muy joven, Fleites subraya su carácter de adolescente en la frontera con la niñez. Más que a Creón, ha de enfrentar a Ismene, una hermana adulta, fea y enamorada de Hemón, llena de regaños y preocupación por la limpieza de la casa, como si asumiera el papel de la madre, la cual, a semejanza del padre, no soportó la contaminación. El miasma, la fuente de la epidemia, ya no es el propio Edipo manchado de sangre, como en Sófocles, sino que este ha muerto a causa de "una simple basurita en el ojo" (FLEITES, 2007, p. XXIV). Sin embargo, con ironía digna del trágico, esta Ismene, tan enajenada por la limpieza, clasifica en su propia definición de "basura", al igual que el tío

\footnotetext{
${ }^{6}$ Reinaldo Montero ha escrito tres: Medea (1997), Antígona, escrita en 2006, publicada en 2009 y representada en 2010, Áyax y Casandra, publicada y estrenada en 2016, pero terminada en 2013 con el nombre de Áyax. A su vez, Abelardo Estorino publicó El tiempo de la plaga en 1997 y Medea sueña Corinto, estrenada en 2008 y publicada en 2012. ${ }^{7}$ Como libro independiente fue editada en 2012 por la editorial Sed de Belleza, en la ciudad de Santa Clara.

${ }^{8}$ También lo es su condiscípulo Maikel Rodríguez de la Cruz, de quien en la misma revista se publica Medea reloaded. Tal coincidencia parece apuntar a trabajos de dramaturgia que debieron emprender como parte de las exigencias docentes, pues ambos estudiaban Dramaturgia en la Facultad de Artes Escénicas del Instituto Superior de Arte.
} 
Creonte. Es ella la que abre y cierra la obra, tratando de hacer entender, al parecer a Antígona y a Hemón, pero más bien al público o a sí misma, argumentos con los que pretende reducir y asimilar lo acontecido a la esfera de su cotidianidad y frustración vital, en una especie de cierre de círculo dentro del cual quedan comprendidos los hechos.

Esta Antígona, capaz de jugar como en la niñez y convertir en mera cancioncita la antinomia sofoclea entre vivos y muertos, es bella, decidida e impulsiva: no necesita razonar su acción, como la heroína griega; simplemente actúa, siguiendo sus instintos. Quiere saber los porqués, acepta los riesgos y hace suyas las emblemáticas palabras de su modelo ático que la definen por el amor y no por el odio, pero con el agregado de "jugar", consciente del papel asumido dentro de la tradición teatral.

Creonte, por su parte, se lleva muy bien con Ismene, con la que comparte hasta los gustos por revistas y fruslerías. Asume sin vacilación su existencia como ente teatral, objeto de innumerables obras y no tiene tapujo en proclamar que irremediablemente es el malo de la historia. Metateatralidad subrayada de nuevo cuando Antígona, al ser arrastrada, pide ayuda e Ismene responde: "A las bambalinas" (FLEITES, 2007, p. XXXI), como para confinar lo heroico a los lindes teatrales.

Creonte, al aceptar su papel, también deja constancia de que a la gente sincera como Antígona, a los héroes, los mataba. Al decretar la muerte de su sobrina se siente feliz, liberado de una carga. Solo cree en él, que está vivo y tiene un hijo, una mujer y un pueblo. Una vez desaparecida Antígona, Ismene, su sobrina tanto carnal como en afinidad, trata, a su vez, de hacerle comprender a Hemón que "no son tiempo de héroes", sino “de seres vivos que necesitamos respirar" (FLEITES, 2007, p. XXXII).

La oposición no es, por tanto, entre vivos y muertos, sino entre "héroes" y gente como ella, que acepta sin rebeldía, se pliega a las circunstancias, pretende una vida tranquila, sin sobresaltos, llena de pequeñeces y razonamientos de una lógica ramplona con que enmarca la trama a modo de pretendida demostración de las virtudes de su opción vital. Tal parece, por tanto, que su mediocridad se impone, pero la acción de Antígona permanece en la memoria, como la propia Ismene admite a su manera, al considerarla una moda adoptada por gente de la calle y por revistas. 
Al autor no le interesa definir la ubicación de la acción: "De esta Tebas sin Tebas" (FLEITES, 2007, p. XXX), afirma Creonte. Mas la contaminación con repertorios modernos y culturales: los cigarrillos, las revistas, la (enseñanza) secundaria estudiada por Antígona, el uso de Rey como apellido, el champú para el pelo, así como el uso de frases referentes a un contexto cubano: "No se juega con los santos, Mayeya" (p. XXIV), "Que crezcan los niños y no los accidentes" (p. XXXIV), pero sobre todo la misma cotidianidad de las acciones de los personajes y el uso de un lenguaje sin el tono elevado, propio de la tragedia, trasladan a nuestros tiempos y a nuestras circunstancias personajes que como Antígona y Creonte no dejan de estar conscientes de su estirpe teatral.

Por otra parte, ciertamente el agón principal de la tragedia sofoclea, el enfrentamiento al tirano, se ha desplazado. No parece esta adolescente haber hecho su opción de enterrar al hermano a sabiendas del riesgo, pues casi hasta el último momento no comprende a dónde la arrastran los guardias, que por cierto aquí son solo mencionados como hombres del pueblo. Tampoco Creonte experimenta ninguna peripecia ni anagnórisis, y mientras su papel ha disminuido, aumenta el de Ismene, quien trata de imponer su visión de las cosas.

Pero si el mundo de aquiescencia y mediocridad representado por Ismene parece triunfar, el reconocimiento que ha despertado la acción de Antígona inscribe la versión de Fleites en la estela sofoclea. Al igual que en la tragedia griega, la heroína paga su desafío, pero la impronta de su acción se impone.

En la obra del joven dramaturgo, el enfrentamiento no es meramente generacional, aunque mucho se insiste en los desplantes de los "mocosos" y sean estos los que actúen según su sentir y sin tapujos, sino con un orden aceptado acríticamente, mantenido por el agotamiento y el ir viviendo en una medianía tranquilizante de sumisión y doble moral.

La Antígona de Fleites, al igual que la de Sófocles, actúa en función de lo que siente como su deber, aunque tenga que desafiar lo establecido. Indudablemente adquiere matices distintos, pero su acción continúa ofreciendo un paradigma. Sigue, pues, siendo Antígona, aún en el ámbito de rebajamiento cotidiano propio de la parodia, de la 
conciencia metateatral y de la fusión de repertorios culturales con que Fleites reclama la atención sobre problemas en que se siente inmerso en el momento presente.

En Jardín de héroes, premiada en 2007 y publicada en 2009, aunque escrita como homenaje a los sesenta años del estreno de Electra Garrigó de Virgilio Piñera, Fleites mantiene una mayor fidelidad al argumento trágico en cuanto no viven todos los personajes - Agamenón, Clitemnestra, Egisto, Orestes y Electra - juntos en el palacio como en la pieza piñeriana, sino que Agamenón ha muerto, de Orestes no se sabe y Electra es el gran estorbo con quien continuamente se topan Clitemnestra y Egisto; pero, no rebajada socialmente, como en Sófocles, ni casada con un campesino, como en Eurípides: solo se pretende ignorarla, puesto que comparte con su padre el afán de notoriedad, no resiste el anonimato y gusta de soñar con héroes: Agamenón y por supuesto Orestes.

La situación inicial puede ser la misma y los personajes llamarse como en la tragedia, pero su accionar, su expresión y su manera de proyectarse está condicionado por la más pedestre cotidianidad, como en la parodia mitológica del siglo IV a.n.e. ${ }^{9}$ Se ha hecho creer a todos que Agamenón murió de una embolia al bañarse después de una suculenta comida; Electra es una chiquilla pecosa que tiene un novio mensajero con quien lee una Ilíada por entregas, y hasta el sueño erótico de este termina en una pesadilla cuando la joven lo rechaza mordida por las hormigas. ${ }^{10}$

Sin embargo, este contraste entre la altura trágica y el giro cotidiano no hace de la obra una simple parodia, puesto que mantiene su centro en la indagación, la cual en esta obra al igual que en Antígona versa sobre el heroísmo y, particularmente, cómo entenderlo en tiempos distantes de la épica. Así, en consonancia con la función de memoria viva de la protagonista sofoclea, está el empeño de esta joven Electra de

\footnotetext{
${ }^{9}$ Aunque no se han conservado piezas, sí hay noticias de como la parodia partía, aparte del mito directamente, de obras trágicas, con un giro inesperado, basado no en la conducta heroica, sino en la vida de personas comunes, y se cita, como ejemplo, el que Orestes y Egisto se convirtieran en amigos (ARISTÓTELES, Poética, 13, 1453a). ${ }^{10}$ Como rememoración posiblemente de los mosquitos que Clitemnestra Pla temía que podrían acabar con la vida de Orestes Garrigó (Cf. PIÑERA, 2002, p. 7).
} 
mantener la figura de Agamenón como ideal, aunque su único recuerdo sea el del padre muerto, añadida la fama plasmada en los cuadernillos que le regala el novio mensajero, en contraste con la imagen de hombre común ofrecida por Clitemnestra o la renuncia de Orestes a convertirse en héroe.

En el encuentro entre madre e hija, la primera señala las preferencias de Agamenón por Electra, en evocación de las sentidas por el personaje piñeriano, y al referir Clitemnestra su sueño con Orestes se burla del mito: "Nada de serpientes ni dragones" (FLEITES, 2007, p. 40); en cambio sí aparecen dos mitades de una papaya, la fruta favorita de Clitemnestra Pla, portadora de su muerte en la obra de Piñera. Al final es Electra la que demanda a la madre por volverse teatral, en contraste con el modelo piñeriano. Como trasfondo de la obra ya no solo se ha de tener en cuenta la tragedia de Sófocles fundamentalmente, sino que a esta se superpone el ofrecido por la Electra Garrigó, a la que se rinde homenaje. Si Orestes Garrigó quería aprender a matar gallos con la técnica de Egisto, en Fleites ya es un consumado gallero que regresa para ver si logra salvar a sus animales al devolver el orden a la casa de los Atridas, de la cual en verdad se siente ajeno, aunque las moscas sartrianas que lo persiguen le sirvan de recordatorio.

La metafórica muerte del gallo viejo, Agamenón, en la pieza de Piñera se concreta en esta nueva obra en una pelea de sus animales concertada entre los dos galleros que se desconocen mutuamente, Egisto y Orestes. La imagen piñeriana también repercute sobre Clitemnestra cuando ve al amante manchado con la sangre de su gallo e interpreta que se ha consumado la muerte de Electra en medio de toda una escena de equívocos, en la cual sale a relucir la historia de la pareja y cómo Egisto ha ido usurpando, además, el puesto de hijo. Por ello, una vez muerto por no pagar su deuda de juego, de "honor", según Orestes, Clitemnestra experimenta la pérdida de Egisto como si fuera la del hijo, al tiempo que niega la filiación con Orestes, asesino del amante muerto a causa de un gallo, en irónico diálogo con Piñera; pero también con ironía en torno a la venganza del Orestes ático, con intertextos sobrepuestos. 
Frente a las pretensiones de Electra, este Orestes reclama ser solo un hombre normal y ofrece, en todo caso, llevársela junto con el novio para vivir tranquilos y felices en una casita en el campo donde podrá sembrar flores, si ella quiere, y llamarlas con los nombres de los héroes: Ulises, Hércules, Aquiles, Héctores y Agamenones. Pero antes quiere conocer a Clitemnestra.

Como en Electra Garrigó, Orestes también se siente atraído por la madre de duros pechos, aunque no sibilinos, y ostentosos adornos, un abanico con crisálida morada no un collar de plata o un marpacífico rojo sobre la túnica negra. Clitemnestra, atormentada por la muerte de Egisto, no lo reconoce. Frente a la imagen de Agamenón, héroe que Electra defiende, opone la del esposo frío y poco atractivo que ella conoció, sin comprender por qué la hija "clama constantemente" (FLEITES, 2007, p. 71) para que se produzca una anagnórisis que le es totalmente ajena tanto a ella como a Orestes; ignorarla sigue siendo el mejor consejo en su parecer. Ni Electra se siente capaz de matar a la madre ni Orestes desea hacerlo, al tiempo que Clitemnestra, con sus recuerdos, ha dado una versión muy distinta del héroe cantado en esa especie de novela por entregas en que se ha transformado la Ilíada en esta pieza.

Una nueva carta con la noticia de la enfermedad del padre adoptivo obliga a Orestes a marcharse, y si Electra, como en Sófocles, pero sobre todo en Piñera, queda sola en el epílogo, no está desolada, sino que, apoyada en los recuerdos de cómo la madre se deshacía de la imagen del padre recortándolo en las fotos y de cómo tornaba sus armas en objetos de uso cotidiano, advierte que ella misma lo vio en algún momento como era y comenzó a olvidar, aunque de vez en cuando la imagen se le aparecía "sucia, sin dueño, hambrienta como un perro". Supo "entonces que solo hay un modo de matar a un héroe: aceptarlo" (FLEITES, 2007, p. 85). No ha necesitado matar a Clitemnestra para, apoyada en sus estrategias, realizarse y asumir su lugar.

No se trata de indagar sobre la justicia (Esquilo), ni sobre lo qué sucede con un individuo sometido a tensiones extremas (Sófocles), ni al absurdo de solo poder contar con uno mismo (Piñera), sino a la preocupación de cómo entender el heroísmo y cómo asimilar su legado 
en tiempos en que la cotidianidad y sus problemas se imponen en un contexto social en que los antiguos héroes solo podrían pervivir como un jardín de flores para hermosear una existencia sin sobresaltos, ofrecida por Orestes a su hermana en lugar de la venganza esperada, aunque finalmente no resulte ni una ni otra.

En Jardín de héroes, quizás motivado por el cuestionamiento de Agamenón Garrigó sobre su papel como personaje trágico, es cuando el problema de cómo enfrentar el legado heroico en tiempos marcados por las necesidades del subsistir cotidiano se torna eje de la obra. Hubo héroes cuyas hazañas se leen a manera de novela, pero aunque Electra se empeñe, como su predecesora trágica, en mantener el recuerdo, no solo la imagen construida contrasta con aquella de quien lo conoció en la vida familiar y experimentó los azares de la convivencia, sino que existen aquellos que, como Orestes, reivindican un modo de vida ajeno a toda heroicidad. Al final, aun una Electra empeñada en mantener la imagen heroica, arriba al convencimiento de que la única opción es aceptar el legado e incorporarlo al bagaje de una vida que continúa por sus propios cauces. Al igual que en Antígona, Fleites se vale de la parodia y de la metateatralidad para hacer evidente su propuesta de reflexión sobre las propias circunstancias, pero con la diferencia de que no solo busca la resonancia del texto sofocleo sino también de la obra de Piñera.

A diferencia de su Antígona y Jardín de héroes, las cuales, no obstante los cambios introducidos, mantienen cierto apego al modelo, Yerandy Fleites, en la tercera obra escrita en aquellos mismos años, Un bello sino, se centra, como implica irónicamente el juego de palabras del título, en el "destino" de la joven Medea, aunque para ello poco conserva de la tragedia de Eurípides, a no ser la pareja de Medea y Jasón, así como el motivo del infanticidio, transformado en aborto. En cambio, altera considerablemente los parentescos, acciones, motivos - con una marcada incertidumbre en su ubicación tanto temporal como espacial - y hasta introduce un personaje, Quirón, que actúa a manera de prólogo y coro, al tomar de este la función de separar las escenas de acción y, con sus cometarios, ofrecer al espectador una perspectiva para enmarcar su comprensión. 
Con una estructura circular, la obra comienza con una joven Medea dormida en un banco de un parque pueblerino frente a la estación de trenes, mientras su nodriza, Cólquida, recién llegada, conversa con su hermano, Creón; escena semejante a la que pone término a la pieza teatral. Enmarcada de esta manera la acción, Medea, muchacha rebelde y decidida, más preocupada por su apariencia - el largo de su cabello, por ejemplo - que de otra cosa, nos irá revelando sus anhelos de felicidad, el despertar de su sexualidad y su necesidad de ser ella misma y no lo que otros pretenden.

En cuanto a la libertad en el manejo del mito, y no solo de la tragedia, la nodriza - de nombre evocador del lugar de origen de la Medea mítica - y Creón son hermanos. Este no es un rey, sino un habitante del pueblo, padre de Jasón y Creúsa, la cual ya murió. Cólquida y Medea, quien ha impuesto a la nodriza su compañía, han acudido al entierro de Esón, quien falleció de viejo a causa del colesterol y también de sus hijas, pues estas se han portado tan mal que ni siquiera aparecieron en el entierro; evocación paródica de motivos míticos fusionados, pues no se menciona siquiera la muerte de Pelias, el usurpador del trono de Esón, cuando sus hijas, bajo la instigación de Medea, procuraban rejuvenecerlo.

A su vez, el reino de Eetes ha devenido una finca; Frixo, el primo que enseñó a besar a Medea; Apsirto, el hermano antojadizo, encerrado por Medea en una cueva para poder marcharse y cuya suerte se desconoce, aunque pueda temerse lo peor. Quirón menciona haber visto al vellocino en una foto junto a Medea y Jasón, dato que en todo caso solo contribuye a la indeterminación de tiempo y lugar, pues la nodriza cuenta sobre la visita del joven Jasón, serio y formal, a la finca de Eetes. En fin, Medea se resiste a abandonar el parque, a pesar de la noche y la llovizna, en espera del novio, y Creón, al contemplarla, sospecha que está embarazada. Al reencontrarse finalmente en este pueblo sin nombre - supuestamente Yolcos, pero tan cercano a la supuesta Cólquide que se viaja en tren -, Jasón y Medea recuerdan sus amoríos junto al río y los temores pasados, pero también el joven expone sus planes para un futuro inmediato y cotidiano de atención al bebé. Es entonces cuando Medea se da cuenta que el problema no es buscar un nombre para el niño, como quiere Jasón, sino que ella necesita encontrar su identidad. 
Como le confesara Jasón a Quirón, domesticarla, además de las ganancias económicas, era su finalidad. A ello se reduce su concepto de heroicidad. Pero Medea, mientras lo oía hablar de lo que les aguarda, ha sentido su ajenidad, su indefinición personal, su deseo de ser por sí misma y, de manera callada, se rebela ante la imposición de seguir planes de otro o el ser arrastrada inconscientemente por hechos fortuitos. En consecuencia, huye y se provoca el aborto. La motivación de esta Medea, por tanto, evoca más que a la heroína de Eurípides a la María de la Medea en el espejo de José Triana (1960), puesto que al igual que esta, o la María Antonia de Eugenio Hernández Espinosa (1967), prima en sus motivaciones la necesidad de encontrar su verdadera identidad frente a la imagen impuesta.

Al final, Jasón, que ha actuado entre bambalinas todo el tiempo, solo aguarda el aplauso, para subrayar la metateatralidad. Medea, de quien nadie sabía a ciencia cierta dónde estaba, regresa y revela a Jasón sus incertidumbres, el aborto y su decisión de continuar sin aceptar manipulaciones de otro, ser ella a pesar de su sino. Jasón se marcha, y la joven vuelve al banco del parque, en que se queda dormida, pues, como concluye Quirón a manera de éxodo, al amanecer se irá en el tren "sin molestar a nadie, con su nostalgia y sus manos sucias" (FLEITES, 2010, p. 45).

El juego entre una supuesta realidad y los personajes míticos presente ya en la Medea de Reinaldo Montero (1996) - se amplía al situar a los personajes en un contexto muy diferente en que se procura, por asociación, la evocación de la tragedia ática para dislocar y subvertir el mito, al tiempo que se borran fronteras entre modelo, tradición y nueva versión dentro de un marco de realidad cotidiana, sin dejar de apelar al teatro dentro del teatro y a los recursos paródicos. Medea ya no es extranjera ni pobre, sino una chica que, como tantas otras adolescentes, se enfrenta al descubrimiento de la sexualidad y la maternidad, sin consciencia aún de ella misma; mientras Jasón es un manipulador que solo en sus montajes se sabe héroe.

Los personajes del antiguo mito devienen simples mortales, cuyos problemas adquieren una dimensión diferente a la luz de las sombras 
que el modelo clásico proyecta sobre ellos; mientras realidad y ficción se conjugan en la metateatralidad para hacer reflexionar sobre problemas comunes de nuestro entorno, pero no por ello exentos de polémicas y de posiciones extremas, como se puede constatar en las constantes referencias a las disposiciones en torno al aborto en la prensa mundial y en los altos índices de adolescentes que afrontan situaciones semejantes.

Si en su Antígona Fleites postula en boca de Ismene que ya no son tiempos de héroes, aunque al final la acción de Antígona sea recordada y deje abierto un resquicio, en Un bello sino, la figura de Jasón, ya muy rebajada por Eurípides, apunta a su total degradación, al tiempo que muy poco queda de la fiera y vengativa Medea; mientras que en Jardín de héroes se postula la asimilación de los héroes como posible ornamento, cuanto más, de una vida ajena a toda "epicidad".

Si más o menos estas tres piezas fueron escritas en los mismos años, la ya por entonces anunciada Ifigenia se separa de ellas por casi una década, quizás porque concurrían circunstancias diferentes. Mientras Antígona, Electra y Medea han dejado una impronta a través de múltiples obras tanto en la Antigüedad como en tiempos modernos y conformado su propia tradición, Ifigenia solo se conoce por las dos piezas que le dedicara Eurípides en momentos distintos de su producción dramática, pues hasta Homero la menciona como Ifianasa y no cuenta con una resonancia semejante a aquella de las heroínas mencionadas; sin olvidar que la suplantación de la hija del Atrida por una cierva y su traslado a tierras de bárbaros se le atribuye al trágico como explicación de cultos existentes en el Ática.

La primera de las dos desde el punto de vista temporal (412-14 a.n.e) fue Ifigenia entre los tauros, la cual ha provocado cuestionamientos entre los estudiosos, pues junto con Helena e Ión conforma un grupo de piezas representadas en la estela dejada por el fracaso de la expedición a Sicilia e identificado por el final feliz, la importancia que adquieren la intriga y el manejo de la ironía así como, se podría agregar, por el contrapunteo entre la verdad aparente y la realidad desconocida. Muchos críticos prefieren considerarlas dramas y aun melodramas, aunque el último rasgo mencionado sea de indudable raigambre trágica; pero en 
todo caso se advierte que con estas piezas Eurípides estaba al borde de un salto cualitativo en el desarrollo del género dramático y en particular de la tragedia. Por su parte, Ifigenia en Áulide se ubica entre las últimas tragedias de Eurípides, y el personaje, en uno de esos cambios de carácter que Aristóteles censuraría en este trágico (Poética, 1454a), pasa de jovenzuela temerosa a heroína que asume conscientemente la muerte para salvar a los suyos en medio de las intrigas y contradicciones de quienes la rodean. Esta última Ifigenia respondería bien al propósito de Fleites de presentar figuras de la tradición clásica como adolescentes, pero no así al cuestionamiento del heroísmo presente en sus otras piezas; mientras la sacerdotisa de Ártemis, salvada por esta y confinada en el Quersoneso táurico (actual Crimea), no podía tornarse mucho más joven, cuando debía encontrarse con un hermano ya hombre, acosado por las Erinias a causa de la muerte de Clitemnestra, al que había dejado muy niño antes de la guerra de Troya. Por ello, al tomar esta obra como modelo y relacionar los personajes, junto al nombre de Ifigenia Fleites aclara "el ocaso de una muchacha" (FLEITES, 2015, p. 411).

Si tanto en su Antígona como en Jardín de héroes del texto clásico solo se mantienen motivos argumentales definitorios, ${ }^{11}$ y en Un bello sino poco queda de la obra de Eurípides, en esta última pieza se subraya la confrontación con el texto de la Ifigenia entre los tauros. En ambas arriban Orestes y Pílades en busca de la estatua de la diosa Ártemis y de la hija de Agamenón, al parecer sacrificada en Áulide, en tanto Ifigenia ha tenido un sueño con una cabellera colgada de unas columnas que le ha hecho temer la muerte de su hermano. Por primera vez en esta especie de tetralogía Fleites utiliza un personaje nombrado Coro en evocación de la consagrada estructura trágica. Sin embargo, también desde un inicio es evidente el contraste: Orestes y Pílades encuentran la imagen de la virgen en una glorieta de un pequeño pueblo rural y ambos se extrañan por la ausencia de restos sanguinolentos como recordatorio de los sacrificios de extranjeros que supuestamente la diosa exigía. El contrapunto entre la situación trágica del modelo y su reducción a la cotidianidad continúa

\footnotetext{
${ }^{11}$ Antígona entierra a su hermano y es condenada por ello. Orestes regresa a la casa paterna, aunque no consume la venganza.
} 
siendo una constante en las versiones del dramaturgo cubano: Orestes no es perseguido por las Erinias, sino sufre una enfermedad, la "erinniasis" (FLEITES, 2015, p. 413); Ártemis es invocada como "santa madre Artemisa, patrona de los tauros, mi virgen negra" (p. 417), como si se tratara de la Virgen de la Caridad, patrona de Cuba; y cuando Coro invoca la genealogía de Ifigenia - uso tan frecuente en Eurípides al presentar un personaje - se califica como "moyugba" (p. 415), saludo yoruba, en clara contaminación de repertorios culturales; sin olvidar que a este Orestes solo le interesa la vuelta de Ifigenia, no la estatua de la diosa, para acabar "de una vez para siempre esta puñetera orestíada" (p. 413). Baste estos ejemplos para subrayar cómo el recurso paródico a través del giro cotidiano y el lenguaje coloquial caracteriza también esta última versión; pero, mientras en las anteriores espacio y tiempo se mantenían indeterminados - al menos explícitamente -, aquí se insiste una y otra vez en que la acción se ubica en la tierra de los tauros, pero que han pasado dos mil años.

A la vez se está en el mismo escenario que en la obra de Eurípides y ante la estatua de la diosa dos milenios después; datación, por otra parte, tampoco determinante, pues no remite a ningún momento preciso, pero que establece un rejuego entre pasado y presente como para subrayar la proyección a través del tiempo del viejo conflicto, o más bien de la situación trágica y sus protagonistas, pero sobre todo la permanencia de estos en el imaginario ficcional.

A su vez esos dos mil años justifican cambios y deterioro de ambiente y figuras como la del envejecido y casi demente Toas, al que se adjudica el epíteto "el de pies ligeros", como si se tratara de Aquiles, a partir de la explicación de Eurípides "reina sobre bárbaros el bárbaro Toante, quien por tener pies tan veloces como alas ha recibido este nombre a causa de la ligereza de sus pies"12 (EURÍPIDES, Ifigenia entre los tauros, v. 32-33). Es este, un rey sin poder, olvidado, al que solo Ifigenia cuida. Igualmente, las Simplégades son los peñascos aludidos del Ponto Euxino entre los que viajan los amigos tan pronto en tren como en barco, al tiempo que el pueblo tiene y no tiene mar: “¿En el mar? ¿En qué mar?

\footnotetext{
${ }^{12}$ Evidentemente se asocia el nombre del rey con el adjetivo thoós, "rápido".
} 
Este pueblo no tiene mar" (FLEITES, 2015, p. 412) por ejemplo. El juego sobre la presencia marina hace pensar en un pueblo como el natal del autor, rural - de "tierra adentro" -, aunque se ubique en una isla, lo cual trae a la mente el verso de Virgilio Piñera: "La maldita circunstancia del agua por todas partes" $(1969$, p. 25), con que iniciara su poema de 1943, La isla en peso, que tantas marcas ha dejado en nuestra literatura.

La relación intertextual se acentúa al poner expresiones del Orestes de Eurípides en boca de Pílades y viceversa, por ejemplo, o se refieren frases de otras obras, que el interlocutor identifica o el autor acota en una nota al pie, como si estuviera pensando más en un posible lector que un espectador. No se necesita una escena de anagnórisis más allá de los nombres, pues tanto Orestes como Ifigenia conocen sus respectivas historias por las lecturas en torno a la saga familiar e intercambian citas de distintas tragedias. También se incorporan alusiones y textos de otras obras, de autores antiguos como Homero, Hesíodo o el ciclo troyano; pero igualmente de cubanos contemporáneos y del propio Fleites. Así, Ifigenia, igual que la adolescente Medea de Un bello sino, se preocupa por el largo de su pelo; hay referencias al "bacilo griego" del que hablara Virgilio Piñera (1960, p. 9); se usa la frase de Abelardo Estorino en su Medea sueña Corinto: "Eurípides, ¿dónde te escondes viejo zorro" (2012, p. 849) u Orestes expresa su aceptación con un "Ese es mi Pílades" (p. 414) que recuerda el "Este es mi gallo" (MONTERO, 2016, p. 29) con que Agamenón congratula a Menelao en Áyax y Antígona, de Reinaldo Montero; aparte de que el paratexto final, tomado de la Ifigenia cruel de Alfonso Reyes, rinde homenaje a este autor. La posición inusual de las palabras alfonsinas sugiere, sin embargo, que el dramaturgo deseaba mantener cierta expectativa o al menos no revelar desde un principio, como en Jardín de héroes, que el contrapunteo con el texto euripideo está mediatizado por la obra del mexicano.

Mientras Orestes reivindica su acción por ser una pieza más de la cadena de crímenes perpetrados por su familia, Ifigenia cambia los mitos, inventa variantes: Agamenón no fue asesinado, sino que no volvió a Micenas, se casó con Casandra y fundó otra familia donde extrañamente se repiten los nombres. Orestes ha asesinado, por tanto, a Clitemnestra 
sin motivo. Las historias se pueden cambiar, y no es fácil decidir cuál es la verdadera. Si a ella la creían muerta y está viva, ¿por qué Agamenón no puede estarlo también? Sin embargo, la sangre de la madre está sobre Orestes, e Ifigenia, al igual que en la obra de Alfonso Reyes, decide no regresar, no porque quiera cerrar el círculo de violencia de su patria, sino que prefiere quedarse en el pequeño pueblito que ha hecho propio y continuar con el cuidado del anciano Toas y sus tareas habituales, aunque ya antes de tomar su decisión se había preguntado: "Por qué siempre hay que estar de un lado o de otro, por qué no se puede estar en ambos lados a la vez, o en un lado que incluya a los dos?"(FLEITES, 2015, p. 438).

No solo hay un continuo y acentuado juego intertextual, sino que, a los componentes metateatrales de la referencia literaria y la representación dentro de la representación, se agrega la autorreflexividad del texto, ${ }^{13}$ en particular en los comentarios del personaje llamado Coro sobre su función en la tragedia por el estilo de este: "No te importa la moral, la dudosa moral, su sospechosa procedencia... Es el héroe y tú el coro. Ser el coro, no te importa qué es un héroe. No te puede importar. Eres el coro, un bulto a la derecha o a la izquierda del espectador, y hasta eso depende... Tantos ayes y suspiros ¿para qué? ¿Para quién?” (FLEITES, 2015, p. 414). Especialmente interesante, aparte de otros comentarios como aquellos de que Ifigenia debe practicar más los "ayes" y los suspiros pues no le quedan bien (p.416), resulta el intercambio entre Coro y Pílades sobre el papel de este en las distintas obras que aparece con solo un breve bocadillo y qué es mejor: si un coro de largas parrafadas o un personaje sin mucho que decir (p. 433-434). Probablemente en este rubro también habría que considerar algo así como el mito dentro de mito en cuanto las variantes existentes ya en los viejos mitos abren la posibilidad - de hecho ya usada por los trágicos atenienses y en particular por Eurípides - de fabular nuevas versiones y parodiarlas también,

\footnotetext{
${ }^{13}$ William García resume los elementos metateatrales apuntados por Richard Hornby en Drama, Metadrama and Perception (1986) como "referencias literarias, la técnica del rol dentro del rol y la auto-reflexividad del texto" y aclara que esta se sustenta también en los comentarios (p. 22 y 33). Aquí se usa el término precisamente con ese sentido de los comentarios sobre el carácter del texto trágico.
} 
Mientras en Ifigenia entre los tauros la intervención de Atenea luego de la frustrada fuga de los griegos sirve para explicar la fundación de cultos en territorios bajo su advocación, en la pieza de Fleites, luego de la decisión de Ifigenia, la partida de los amigos en el tren y hasta de Coro, que tiene que desempeñar su función en otros lugares, hay un amplio éxodo. Ifigenia, por tras recibir una foto de la familia dejada por el hermano y asegurarle a Toas que lo seguirá atendiendo, reflexiona sobre las Ifigenias que se van y las que, como ella, prefieren su realización en donde han vivido y han de morir: "Hay Ifigenias que se van y otras que nunca aprendieron. Yo soy de las que no aprendí. Yo soy de las que no aprendió a escapar. Es algo que no está en mí. Tenga a bien cuidar mis sentimientos, Madre Artemisa. Téngame, téngame, téngame. Pueblo mío. Pueblo Blanco. Como una rosa de tierra acodado en el pecho de tu gente." (FLEITES, 2015, p. 450). Palabras que no solo sellan la obra, sino la tetralogía, puesto que la acción de las cuatro piezas se sitúa en un pueblo rural en que personajes y conflictos de las antiguas tragedias subsisten en la cotidianidad y, a su vez, las devuelve a los orígenes, en cuanto "dramas de familias en poblaciones pequeñas", tal como las definiera Alejo Carpentier (1994, p. 54).

En esta versión, quizás porque al ser la cuarta de una tetralogía, le correspondía el lugar asignado al drama satírico, la parodia burlesca ocupa un papel mucho mayor que en las precedentes y hasta pone en solfa el propio género trágico. Pero lo cierto es que más allá de los recursos paródicos ya utilizados por Aristófanes y la comedia media o por el propio drama satírico, entre tantos rejuegos literarios con el avispado espectador o lector, la pieza mantiene presente conflictos actuales que atañen a la realización personal y social. A ello, sin olvidar que se hace eco de la indagación entre lo aparente y lo real que recorría la pieza de Eurípídes y que aquí se amplifica, posiblemente se deba el título de Ifigenia (tragedia ayer), aunque el adverbio temporal mantenga la duda.

Si Ismene estaba convencida de que ya no era tiempo de héroes, si Jasón es un mero manipulador y Orestes se niega a ser héroe en las piezas anteriores, en esta ultima el hijo de Agamenón, a pesar de reivindicar su acción condicionada por la saga familiar, queda manchado por la sangre 
derramada sin excusa aparente y con ello tendrá que vivir sin recuperar una vida de familia. Ifigenia, quien confiesa que nunca se ha sentido heroína, opta por la vida tranquila de un pueblo olvidado pero donde están sus afectos y las pequeñas cosas acostumbradas que la hacen sentirse ella misma, sin perder el sentimiento filial. El conflicto quedó por tanto en el ayer, sea hace dos mil años o cuando tomó su decisión. Así pues, aunque mantiene Fleites presente algunas constantes, ni Ifigenia es tan joven, aunque el personaje lo pretenda, ni se cuestiona cómo asimilar a los héroes, al tiempo que, si en Un bello sino se incorporaba el problema del embarazo adolescente, es la emigración y la división familiar el tema que en medio de tanta parodia literaria se impone finalmente en esta versión de la Ifigenia euripidea.

La "tetralogía" de Yerandy Fleites nos muestra un abanico de posibilidades en cuanto a la recepción clásica se refiere y un cambio de actitud en relación con la generalmente asumida en la centuria pasada, cuando la versión moderna podía mantener la acción con sus vestiduras tradicionales o trasladarla al presente hasta con nombres distintos, pero casi siempre con un carácter serio, aunque en el teatro cubano a partir de la iniciática Electra Garrigó el camino a la desacralización en la consideración de las obras clásicas estaba abierto, así como la búsqueda de la apropiación para repensar las propias circunstancias.

Sin embargo, es evidente que en la actual centuria priman lo metateatral y la fusión de géneros y de repertorios culturales, aunque los personajes mantengan sus vestiduras clásicas, se ubiquen en los mismos lugares o en todo caso se busque una indeterminación en el tiempo y en el espacio, aunque no falten rupturas al introducir referencias a usos nacionales o contemporáneos. Ya no se trata del mero diálogo entre dos textos, sino con la misma tradición conformada por las distintas versiones a través del tiempo, o aún más, una de ella puede actuar como una especie de capa intermedia, sin dejar de aludir de manera puntual a otras versiones. A través de la desacralización paródica, la fusión de repertorios, el lenguaje cotidiano, el juego intertextual, y la subrayada metateatralidad, sin menospreciar las posibilidades del humor y la ironía, se busca un acercamiento a un público actual que en las versiones de 
Fleites parece ser tan joven como las protagonistas y el mismo autor, quien procura, de manera amena y en medio del juego literario, asumir inquietudes de una nueva generación que necesariamente ha de afrontar circunstancias diferentes a las de un pasado cercano con la carga de estereotipos sociales que ello supone.

Aunque no sea posible generalizar, y tanto los recursos como las proporciones en que se utilizan pueden variar de un autor a otro, y aún en un mismo dramaturgo, indudablemente la recepción clásica actual se diferencia en la forma de asumirla en otros momentos. Algunos críticos han usado distintos términos para calificar las diferencias que advierten, y no ha faltado quien mencione el fin de los mitos, pero lo interesante es que este proceso antropofágico, pudiéramos decir para aprovechar la fuerza metafórica del concepto, del cual surge una nueva versión cargada con la fuerza crítica y desacralizadora de la burla y el rejuego irónico, continúa el diálogo con los clásicos, posiblemente como vía atrayente y culturalmente aceptada, para plasmar los puntos de vista del dramaturgo y provocar en el espectador la propia reflexión, tal como se propusieron en su momento los trágicos áticos.

\section{Referencias}

CARPENTIER, A. La tragedia restituida. In: . Letra y solfa. Teatro. La Habana: Letras Cubanas. p. 53-54.

ESTORINO, A. Medea sueña Corinto. In: Habana: Alarcos, 2012. p. 849-863.

EURÍPIDES. Ifigenia entre los tauros. Traducción de José Luis Calvo. In: . Tragedias. Madrid: Gredos, 2000. v. II. p. 281-341.

FLEITES, Y. Antígona. Tablas, La Habana, v. LXXXVII, n.3-4, p. XXIVXXXII, 2007.

FLEITES, Y. Ifigenia (tragedia ayer). In: FUNDORA, E. (Org.). Dramaturgia cubana contemporánea. México: Editorial Paso de Gato, 2015. p. 409-450.

FLEITES, Y. Jardín de héroes. La Habana: Casa editorial Abril, 2007. FLEITES, Y. Un bello sino. Matanzas: Ediciones Matanzas, 2010. 
GARCÍA, W. Sabotaje textual/teatral contra el modelo canónico: Antígona-Humor de Franklin Domínguez. Latin American Theatre Review, Lawrence, v. 31, n. 1, p. 15-29, Fall 1997.

MIRANDA, E. Calzar el coturno americano. La Habana: Alarcos, 2006.

MIRANDA, E. Recepción y resonancia de Electra Garrigó, la obra iniciática de Virgilio Piñera. In: ROJAS, J. E. (Org.). Tradición Clásica: propuestas e interpretaciones. México: UNAM, 2015. p. 173-192.

MONTERO, R. Áyax y Casandra. La Habana: Alarcos, 2016.

PIÑERA, V. La isla en peso. In:

UNEAC, 1969. p. 25-42.

PIÑERA, V. Piñera teatral. In: . La vida entera. La Habana: Instituto del Libro, 1960.

PIÑERA, V. Teatro completo. La Habana: Letras Cubanas, 2002.

REYES, A. Ifigenia cruel: poema dramático. México: Ediciones La Cigarra, 1945.

Recebido em: 11 de fevereiro de 2018. Aprovado em: 5 de março de 2018. 